\title{
Improving the quality of care in a public hospital in Guatemala
}

\author{
Erick Estuardo Estrada, Guatemala City, Guatemala
}

Guatemala is located in Central America with an estimated population of 16.6 million people, of which $54 \%$ are women. Hospital General San Juan de Dios is one of the two major hospitals in our public health system and the only one that provides free gynecological cancer care to our population. After years of collaborative hard work in 2015, the Department of Gynecology and Obstetrics of Hospital General San Juan de Dios established the Gynecology Oncology Clinic. The cervical cancer rate in Guatemala is strikingly high, as is the case in most low-middle income countries of Latin America. There are no effective screening programs for cervical cancer in our country. Cervical cancer and breast cancer rank as the most common cancers in women and unfortunately most are diagnosed in advanced stages.

Since 2015 the number of patients seen in our clinic has increased from an average of 264 patients per year to 965 patients per year. Referral from other public health

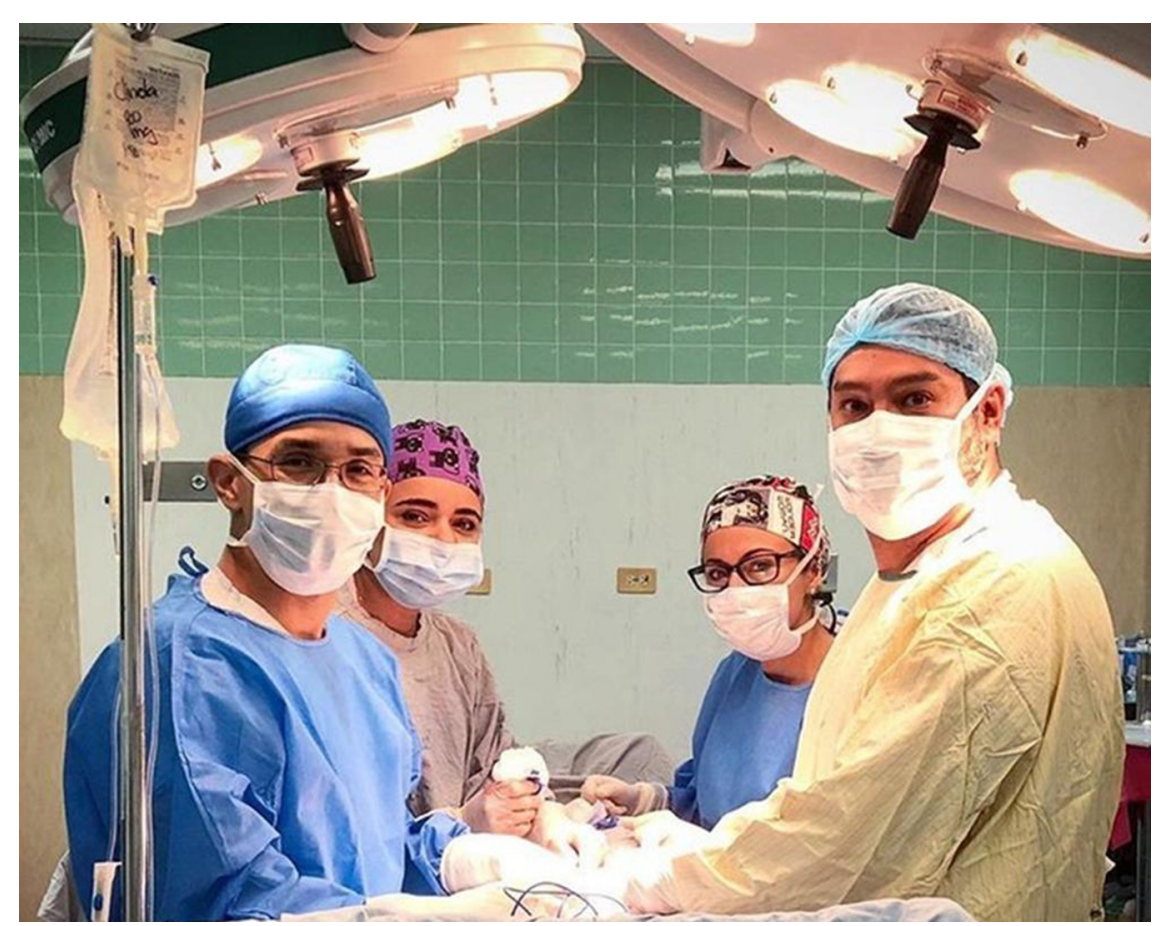

Figure 1 Minimally Invasive Surgery Unit, Gynecology Oncology Hospital General San Juan de Dios.

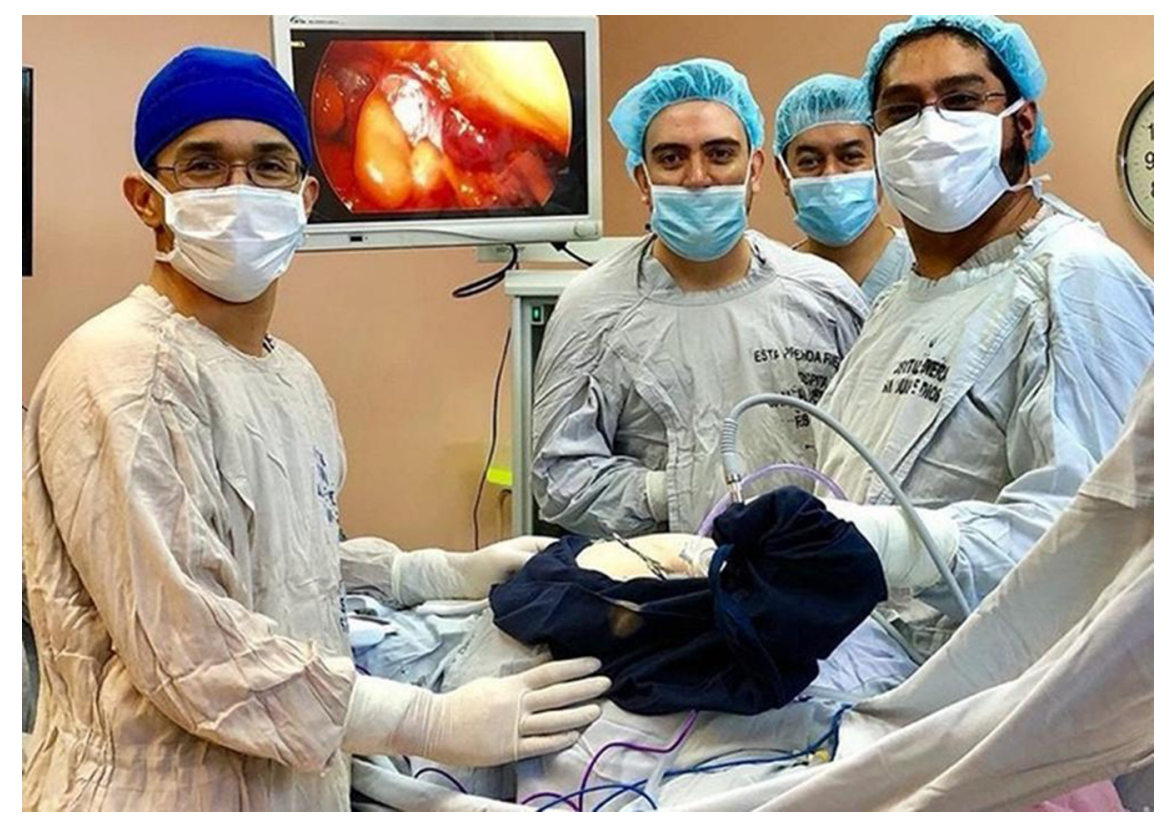

Figure 2 Delivering the best cancer care. system hospitals and private institutions has also increased. As a multidisciplinary department, we are able to perform aggressive procedures for cancer treatment and established a quick referral for patients in need of neo-adjuvant chemotherapy or additional adjuvant therapy. The lack of radiotherapy in the public health system left many women without adequate treatment. Through various meetings with the Ministry of Health, we are now able to refer patients to a private institution and the costs are absorbed by the Ministry of Health.

The desire to deliver the best cancer care gave us an impetus to acquire laparoscopy equipment in order to offer minimally invasive surgery to our patients according to standards around the world. On November 3, 2015 we performed the first laparoscopic hysterectomy and extra-peritoneal para-aortic lymphadenectomy on a patient with grade 3 adenocarcinoma of the uterus. Gradually, we were able to do laparoscopic radical hysterectomy and other procedures through the minimally invasive approach. In 2017 we presented the first study performed in Central America for the validation of sentinel lymph node in cervical cancer in our institution. We found 


\section{Corners of the World}

a pooled detection rate of $85.2 \%(95 \% \mathrm{Cl}$ $82.3 \%$ to $91.6 \%$ ). The positive predictive value and specificity were both $100 \%$ and sensitivity and negative predictive value were $90 \%$ and $97 \%$, respectively. We are currently exploring the feasibility of sentinel lymph node mapping in endometrial cancer, as it has become the third most common cancer diagnosis in our clinic. All our residents and medical students have had incredible educational and personal experiences that will must surely positively impact their professional life. We still have to struggle with the scarcity of certain products, but none of these limitations will deter our spirit and the mission to deliver the best in cancer care for those in most need.

Correspondence to Dr Erick Estuardo Estrada; mderickestrada@yahoo.com

Collaborators Julio Lau de la Vega, Hedi Andrade Deman, Pedro Hernandez, Hugo Ruano Chinchilla

Funding The authors have not declared a specific grant for this research from any funding agency in the public, commercial or not-for-profit sectors.

Competing interests None declared.
Patient consent Not required.

Provenance and peer review Not commissioned; internally peer reviewed.

(c) IGCS and ESGO 2019. No commercial re-use. See rights and permissions. Published by BMJ.

D Check for updates

To cite Estrada EE. Int J Gynecol Cancer 2019;29:439-440..

Accepted 3 January 2019

Published Online First 23 January 2019

Int J Gynecol Cancer 2019;29:439-440.

doi:10.1136/ijgc-2018-000183 